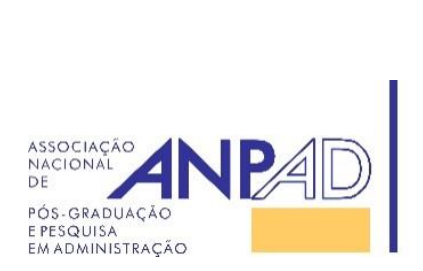
Disponível em
http://www.anpad.org.br/rac
RAC, Rio de Janeiro, v. 22, n. 1, art. 2,
pp. 23-45, janeiro/fevereiro, 2018,
http://dx.doi.org/10.1590/1982-7849rac2018160123
(cc) EY

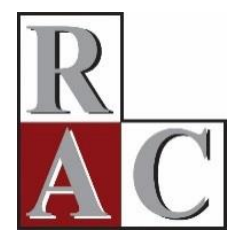

\title{
Desempenho de Empresas Diversificadas: Evidências da Indústria de Transporte Aéreo dos Estados Unidos
}

Diversified Company Performance: Evidence from the United States Airline Industry

Henrique Machado Barros ${ }^{1}$ Adriana Bruscato Bortoluzzo 2 Lucas Mello de Campos Arruda ${ }^{2}$

Centro Universitário FEI-SP ${ }^{1}$ Insper $^{2}$

Artigo recebido em 16.06.2016. Última versão recebida em 21.08.2017. Aprovado em 27.08.2017. 


\title{
Resumo
}

Este artigo analisa o efeito da estratégia de diversificação relacionada no desempenho das firmas. Com base em uma amostra de cerca de 70\% das companhias aéreas dos Estados Unidos, o trabalho investiga a relação entre o grau de diversificação e a lucratividade das firmas. Foram utilizados modelos de regressão linear múltipla com dados longitudinais (i.e., 6 anos), cuja estimação dos parâmetros foi feita pelo método dos momentos generalizado (GMM). A pesquisa identifica que o padrão de relação entre a extensão da diversificação e o desempenho é curvilíneo na forma de U-invertido. Portanto, a expansão do escopo dos negócios das firmas com a estratégia de diversificação relacionada aumenta os esforços de coordenação que, a partir de certo momento, penalizam os benefícios dessa estratégia.

Palavras-chave: estratégia; diversificação; desempenho; transporte aéreo.

\begin{abstract}
This paper analyzes the effect related diversification strategy has on firm performance. Based on a sample of $70 \%$ of US airlines, this piece of research investigates the relationship between the degree of diversification and corporate profitability. Multiple linear regression models of panel data (i.e., 6 years) were tested, with model parameters estimated by the Generalized Method of Moments (GMM) technique. We identified that firm performance followed an inverted-U curvilinear pattern. That is, boundary-spanning activities of related diversified firms increase coordination efforts to the extent that, at some point, the benefits of this strategy are offset.
\end{abstract}

Key words: strategy; diversification; performance; air transport. 


\section{Introdução}

A estratégia de diversificação é reconhecida como um dos meios para as organizações buscarem o crescimento (Ansoff, 1958), e a literatura de estratégia empresarial tem identificado os antecedentes e os efeitos daquela estratégia (Mackey, Barney, \& Dotson, 2017; Rawley, 2010). A literatura de estratégia classifica a diversificação como relacionada (i.e., related diversification) ou não-relacionada (i.e., unrelated diversification). A primeira se caracteriza pelo fato de a firma expandir as fronteiras organizacionais para negócios que apresentam tecnologias/infraestruturas parecidas com as do negócio original; já a última retrata o movimento das organizações para negócios que não compartilham tal similaridade (Furrer, 2015). De modo geral, o que tanto a literatura de estratégia (e.g., Kumar, 2013) quanto a literatura de finanças (e.g., Shawky, Dai, \& Cumming, 2012) têm defendido é que a diversificação pode criar mais valor quando os negócios são relacionados. Isso se dá porque a diversificação relacionada permite que as organizações aproveitem sinergias entre os negócios e/ou alcancem economias de escopo (Furrer, 2015). Assim, os benefícios proporcionados pela estratégia de diversificação relacionada superam os custos de coordenação decorrentes de a firma ter mais de um negócio (Rawley, 2010).

Todavia, apesar de as evidências empíricas sinalizarem que empresas que diversificam relacionadamente obtêm, em média, melhores desempenhos, comparadas com as que não diversificam ou que diversificam não-relacionadamente (Sakhartov \& Folta, 2014), pouco se sabe sobre a variabilidade do desempenho entre as firmas que adotam a diversificação relacionada como estratégia de crescimento (Hashai, 2015). Conforme observa Zhou (2011, p. 624), "os limites da diversificação relacionada estão subestudados".

Nesse sentido, o objetivo desta pesquisa é identificar se o desempenho das empresas que expandem seus negócios de forma relacionada é afetado pelo grau com que diversificam suas atividades econômicas. Além de tentar contribuir com a ampliação do conhecimento sobre o impacto que a expansão das fronteiras horizontais tem sobre o desempenho das firmas, esta pesquisa almeja colocar mais luz na decisão dos gestores que se deparam com a possibilidade de buscar o crescimento corporativo por meio da estratégia de diversificação relacionada.

O presente trabalho foi desenvolvido a partir do levantamento de informações sobre corporações atuantes em negócios associados ao transporte aéreo nos Estados Unidos. O transporte aéreo normalmente apresenta um contexto bastante difícil para as firmas terem bom desempenho (Barros, Liang, \& Peypoch, 2013) e muitas delas se caracterizam por atuar em mais de um negócio, mas que compartilham recursos entre si, como o transporte de passageiros e o transporte de carga, ou seja, negócios relacionados (Holloway, 2008). Nesse sentido, o transporte aéreo dos Estados Unidos é um contexto empírico adequado para se investigar o fenômeno de interesse. Assim, foram estudadas corporações comprometidas em algum grau com a estratégia de diversificação relacionada naquele mercado. Os dados foram consolidados no nível de corporação e foram coletados por seis anos, compreendendo os principais estágios do ciclo de negócios (i.e., expansão, contração e declínio) de transporte de passageiros, mas que, dada a relação entre os negócios, também se aplica aos demais negócios com os quais as corporações estavam envolvidas. A amostra resultante compreende cerca de $70 \%$ das companhias aéreas dos Estados Unidos com o tipo de estratégia de interesse desta pesquisa.

A próxima seção apresenta a revisão da literatura e a hipótese de pesquisa a ser testada. Em seguida, a seção com a metodologia é detalhada. Logo após, são apresentados os resultados, seguidos pela respectiva discussão e, por fim, seguem as conclusões. 


\section{Fundamentos Teóricos e Hipótese de Pesquisa}

\section{Diversificação no transporte aéreo}

O setor de transporte aéreo apresenta condições desafiadoras para o desempenho das firmas (Borenstein, 2011). Por exemplo, em 2012, as companhias aéreas geraram cerca de US\$ 228 por passageiro embarcado, mas o lucro líquido médio por passageiro ficou em torno de US\$2,56. No mesmo ano, as empresas aéreas tiveram Retorno sobre o Capital Investido em torno de 4\%, mas um Custo Médio Ponderado de Capital ligeiramente abaixo de 7,5\%. Nesse cenário, as empresas do setor buscam na diversificação uma alternativa para alcançar maior rentabilidade (International Air Transport Association [IATA], 2013).

No passado, companhias aéreas, como Continental e PanAm, entraram no setor hoteleiro, por exemplo, porque seus gestores acreditavam que era um negócio que eles conseguiam entender relativamente bem. Além disso, acreditava-se que o serviço de hospedagem seria uma importante base de diferenciação pelo fato de estar vinculado a uma possível compra desse serviço pelo passageiro transportado pela mesma companhia aérea (Holloway, 2008). A Scandinavian Airlines (SAS), por exemplo, que chegou a ser proprietária de um hotel em Copenhage na década de 1960, diversificou seus negócios para operações de catering, para voos fretados e mesmo para operadoras de turismo nos anos seguintes. Hoje, a empresa atua de forma bem mais focada, concentrando-se no transporte regular de passageiros, ainda que na Finlândia e na Noruega conte com duas outras empresas para realizar voos regionais; a Blue1 e a Widerøe, respectivamente (SAS, 2013).

Atualmente, é comum que as companhias aéreas, ao diversificarem os negócios, o façam a partir do transporte aéreo regular de passageiros para o transporte de carga e/ou para o voo charter de passageiros (Ashford, Mumayiz, \& Wright, 2011). Esses três negócios permitem o compartilhamento de recursos, sejam eles físicos, humanos ou financeiros (Holloway, 2008). No caso do transporte de carga, as empresas fazem uso do compartimento inferior do avião para esse segmento (belly cargo). Dessa forma, o tipo de carga transportada é caracterizado, geralmente, por pacotes ou mercadorias de tamanho médio a pequeno (Kupfer, Meersman, Onghena, \& Van de Voorde, 2017). A venda do serviço é feita por meio de agências da própria companhia aérea ou por meio de empresas especializadas, tais como agentes de carga ou mesmo integradores de grande porte - e.g., DHL, UPS, Fedex, entre outros (Chang \& Chang, 2009). Uma particularidade geral do transporte de carga é a falta de demanda nos dois sentidos da rota, ou seja, em um voo de ida e volta, apenas um dos trechos (ida ou volta) apresenta grande demanda pelo transporte de carga (Popescu, Keskinocak, \& Mutawaly, 2010). Assim, o compartilhamento do uso da aeronave permite a redução de custos (Kupfer et al., 2017).

Por outro lado, a carga é comumente vista como um subproduto. Assim, uma vez alocados os custos diretamente relacionados a ela (e.g., manuseio de solo, marketing, vendas e combustível adicional devido ao acréscimo de peso), qualquer diferença potencial em relação à receita obtida é utilizada para compensar os custos relacionados ao transporte de passageiros (Merkert, Van de Voorde, \& de Wit, 2017). Neste caso específico, o negócio de carga não compartilha os custos de tripulação, da manutenção das aeronaves, do seguro, da depreciação do equipamento e de grande parte do combustível total (Holloway, 2008). Em outros casos, no entanto, algumas companhias fazem uma alocação mais completa dos custos totais, tal como o uso do volume ocupado para alocação de custos operacionais diretos, a alocação específica dos custos que possam ser diretamente relacionados à carga (e.g., vendas, manuseio de solo) e uma alocação proporcional à soma de custos, para o caso de despesas administrativas e outras despesas indiretas (Chang \& Chang, 2009). Em qualquer um dos casos, assim como no negócio de charter, os recursos disponíveis para a companhia são, em grande parte, utilizados de forma compartilhada entre os negócios da firma (Popescu et al., 2010).

O negócio de transporte de passageiros no modo charter, por sua vez, possui características particulares no que se refere à demanda e ao processo de vendas e canais de distribuição. A operação charter permite à companhia aérea gerar receitas complementares e fazer maior uso de seus ativos (i.e., 
aeronaves) em épocas específicas do ano, já que o mercado é caracterizado pela sazonalidade (Wu, Hayashi, \& Funck, 2012). O processo de venda ganha especial participação de canais indiretos, tais como agências de viagem, operadores turísticos e/ou consolidadores. Nesse processo, a operação pode ser vendida tanto para o voo completo, dedicado aos passageiros do mesmo grupo ou combinação de grupos alocados pela empresa que originou a solicitação do charter, quanto pode ser caracterizada pela venda específica de assentos ou grupo de assentos em voos regulares (Holloway, 2008). Portanto, a configuração do portfólio de negócios das empresas do setor suscita o questionamento sobre até onde a diversificação é capaz de contribuir para o melhor desempenho das empresas, especialmente pelo fato de elas atuarem em negócios relacionados.

\section{A relação entre a diversificação relacionada e o desempenho}

Um dos principais argumentos para justificar a estratégia de diversificação dos negócios é a diminuição de riscos - i.e., caso um dos negócios não apresente o resultado esperado, a firma ainda tem outros negócios que poderão compensar o negócio com desempenho insatisfatório. A noção de diversificação de risco se apoia, em grande parte, em trabalhos precursores na área de finanças e que deram origem à moderna teoria de carteiras (Chiu, Wong, \& Li, 2012). A partir da premissa de que um investidor é avesso ao risco (e, portanto, deseja uma pequena variância dos retornos) e que deseja maximizar o retorno esperado, o ponto central da teoria de Markowitz (1952) é que a diversificação de investimentos leva à redução do risco de uma carteira por causa das correlações imperfeitas entre as taxas de retorno dos componentes da carteira. Trabalhos posteriores (e.g., Lintner, 1965; Sharpe, 1964) se basearam na elaboração teórica de Markowitz (1952) para desenvolver o Modelo de Apreçamento de Ativos (Capital Asset Pricing Model [CAPM]), que separa o risco em sistemático (i.e., risco que afeta todos os retornos e não pode ser eliminado) e não-sistemático (i.e., inerente ao próprio negócio), reforçando que a diversificação da carteira de investimentos é a forma mais eficaz de se evitar o risco não-sistemático (Schulmerich, Leporcher, \& Eu, 2015).

Apesar de os fundamentos da moderna teoria de carteiras serem usados para a discussão de investimentos em ativos financeiros, a lógica também se aplica à diversificação dos negócios das firmas. No entanto, neste contexto, o argumento de que a diversificação de risco é eficaz se torna questionável, pois os proprietários da firma podem utilizar mecanismos mais eficientes no mercado para diversificar seus investimentos (Yang, Narayanan, \& De Carolis, 2014). Por exemplo, os proprietários de uma dada firma podem comprar ações de outras firmas ou eles podem alocar seus recursos em fundos de investimento administrados por especialistas em tais atividades; em ambos os casos sem a necessidade de se ter propriedade em uma firma para entrar em novos negócios (Shawky et al., 2012). Portanto, a diversificação motivada pela mitigação de risco retrata, na verdade, a diversificação de risco de empregabilidade dos gestores (e.g., Amihud \& Lev, 1981). Como a diversificação com vistas à diversificação de risco ocorre para negócios não-relacionados (i.e., unrelated diversification) e, portanto, motivada por fatores que não estão associados à criação de valor para o acionista, é comum que as corporações com essa estratégia sejam penalizadas. Esse fenômeno ficou conhecido na literatura especializada como diversification discount, ou seja, o valor das corporações (i.e., grupo econômico) que atuam em vários segmentos de negócio é menor do que o somatório dos valores de todos os negócios de atuação da corporação se cada negócio fosse uma firma independente (Laeven \& Levine, 2007; Mackey et al., 2017).

O conflito de interesses entre acionistas e gestores é conhecido como problema de agência e emerge em um contexto de assimetria de informação, em que ambas as partes (agente e principal) são maximizadoras de utilidade e no qual o agente é racional e avesso ao risco (Jensen \& Meckling, 1976). Para mitigar o problema de agência, o principal pode criar recompensas para o bom comportamento do agente por meio de desenhos contratuais específicos (e.g., incentivos pecuniários e/ou cessão de propriedade da empresa) e/ou pode criar sistemas de controle adicionais (e.g., conselhos de administração), de tal modo que potenciais atividades extravagantes do agente sejam minimizadas (Eisenhardt, 1989; Jensen \& Meckling, 1976; Latham \& Braun, 2008). Tais instrumentos acabam por induzir as corporações a buscar a estratégia de diversificação com maior potencial de criação de valor, e que tende a ser a estratégia de diversificação relacionada (i.e., related diversification). No caso da 
diversificação relacionada, o aumento no escopo da firma permite que ela explore mais os potenciais benefícios gerados por essa estratégia. Empresas que atuam em negócios relacionados podem alcançar economias de escopo nas dimensões operacional, financeira e anticompetitiva (Furrer, 2015). Por exemplo, além do mercado interno de capitais, que pode ser útil quando os recursos financeiros desejados não estão acessíveis no mercado, firmas com maior escopo podem compartilhar recursos tangíveis, como infraestrutura produtiva (Hashai, 2015; Rawley, 2010), e intangíveis, como marca e competências (Mackey et al., 2017).

Segundo Palich, Cardinal e Miller (2000), vários trabalhos já foram realizados com o objetivo de avaliar e mensurar a relação entre a estratégia de diversificação e o desempenho das firmas. De acordo com os autores, a relação entre a diversificação e o desempenho é explicada por um formato curvilíneo de U-invertido. Nele, empresas com um único negócio e empresas diversificadas com negócios nãorelacionados compõem as caudas da curva, enquanto que empresas diversificadas com negócios relacionados se localizam no pico da curva. Tal interpretação leva a uma suposição de que a heterogeneidade no desempenho das firmas está associada somente ao tipo de estratégia. No entanto, a literatura recente de estratégia tem sinalizado que a variabilidade no desempenho não é decorrente do tipo de estratégia em si, mas dos mecanismos e das implicações associadas a cada tipo de estratégia (Hashai, 2015). Zhou (2011), por exemplo, identificou que a similaridade de insumos entre o negócio principal e um novo negócio aumenta a probabilidade de a firma se inserir neste novo negócio. Além disso, Kumar (2013) observou que o negócio principal exerce influência sobre os demais negócios e que isso tem um impacto negativo na produtividade dos demais negócios relacionados de modo que os subsídios fornecidos ao negócio principal podem ser importantes fontes de ineficiência para a corporação.

Como os custos de coordenação de múltiplos negócios também aumentam na medida em que a firma diversifica mais, se as corporações não conseguem compensar esses custos com economias de escopo e/ou sinergias, acabam sendo penalizadas. Assim, o esforço de coordenação de múltiplos negócios pode, em algum momento, suplantar os benefícios advindos da diversificação (Hashai, 2015; Mackey et al., 2017; Rawley, 2010; Zhou, 2011). Como os custos de coordenação são crescentes quanto maior for o escopo da firma (Hashai, 2015), argumenta-se na presente pesquisa que o padrão curvilíneo (U-invertido) deve ser observado mesmo entre as empresas com estratégia de diversificação relacionada. Em outras palavras, empresas que diversificam para negócios relacionados são capazes de obter os benefícios de economias de escopo, mas na medida em que os demais negócios vão crescendo, as economias alcançadas começam a ser descontadas pelos maiores esforços de processamento de informação e de coordenação dos negócios (Rawley, 2010; Zhou, 2011). Além disso, na medida em que os negócios adjacentes vão se tornando mais relevantes para a corporação, eles começam a competir por recursos com o negócio principal e o poder exercido pelo negócio principal pode comprometer os ganhos de eficiência da corporação como um todo (Kumar, 2013). Sendo assim, a hipótese da presente pesquisa é que, tudo mais constante, mesmo quando as empresas adotam a estratégia de diversificação relacionada:

Hipótese: A relação entre o grau de diversificação (ou de foco) e o desempenho é curvilínea no formato de U-invertido.

\section{Método de Pesquisa}

\section{Dados e amostra}

Os dados financeiros das empresas foram obtidos a partir do Form 41 (Schedule P-1.2) disponibilizados pelo Bureau of Transportation Statistics do Departamento de Transportes dos Estados Unidos (DOT - https://www.transtats.bts.gov/). Já os dados relativos à frota de aeronaves de cada companhia aérea, incluindo o modelo e a capacidade de assentos, apesar de poderem ser coletados a partir do DOT, foram extraídos utilizando-se a ferramenta Fleet $P C$ da base de dados da OAG 
(https://www.oag.com/). Optou-se por utilizar os dados financeiros disponibilizados pelo DOT, pois, além de serem públicos, permitiriam uma amostragem maior do que se a pesquisa fosse conduzida apenas com empresas de capital aberto (Hannigan, Hamilton, \& Mudambi, 2015).

A análise contemplou um período de seis anos (i.e., 1995, 1996, 1998, 1999, 2001 e 2002). Esse período foi escolhido para garantir que as principais fases do ciclo de negócios do setor (i.e., expansão, declínio e contração) fossem capturadas. Tais fases foram identificadas a partir de um indicador produzido por especialistas (i.e., Morgan Stanley Airline Index) e ratificadas tanto a partir da literatura (Liehr, Größler, Klein, \& Milling, 2001; Pierson \& Sterman, 2013) quanto a partir de um índice de desempenho das empresas de transporte aéreo disponível publicamente - i.e., NYSE Arca Airline Index. Muito embora dados mais recentes estivessem disponíveis na ocasião da coleta, a opção pelo uso de dados mais antigos foi guiada pela maior facilidade de caracterização das fases do ciclo de negócios do setor, que se tornaram mais curtas a partir de 2007. Mesmo o período de análise não sendo contemporâneo, isso não o desqualifica, uma vez que os dados coletados servem ao propósito do trabalho de investigar a relação entre a diversificação e o desempenho. D. J. Miller (2006), por exemplo, usou dados relativamente defasados (i.e., 1990) em sua análise sobre os efeitos da diversidade tecnológica no desempenho de empresas de alta tecnologia.

A abordagem longitudinal foi escolhida, pois permitiria controlar o efeito temporal, reduzindo possíveis vieses relacionados às flutuações ocorridas em cada fase do ciclo de negócios do setor. Optouse ainda por consolidar os dados trimestralmente para aumentar a quantidade de tempos observados, isto é, 4 trimestres para cada período de interesse (expansão, declínio e contração), totalizando 12 instantes de tempo. Apesar de os livros-textos indicarem que, para a análise de regressão em painel, há necessidade de se coletar os dados em pelo menos 2 instantes de tempo para que os modelos sejam estimados de forma adequada (Wooldridge, 2010), este trabalho utilizou um número maior. Isso permitiu que as análises contemplassem variáveis explicativas defasadas (Bond, 2002) e que os estimadores fossem consistentes e não viesados (Bhargava \& Sargan, 1983). Assim, a extensão do período forneceu um número de observações que não comprometeu a inferência estatística. Ainda que um horizonte de tempo maior pudesse ser de interesse, o benefício de se coletar dados para um período maior não parecia justificar, conforme indicado na literatura citada, o esforço necessário para sua realização. Isso porque uma das variáveis de controle (i.e., market share) empregada neste trabalho demandava a consolidação de um volume muito grande de informações; só para o período estudado, por exemplo, foram consolidadas informações de 34.700 pares de cidades O\&D (origem e destino).

No período da análise, havia cerca de 90 companhias aéreas listadas pelo DOT, dentre as quais companhias aéreas que não atuavam (ou não reportavam atuar) em mais de um negócio, possivelmente pelo pequeno porte delas, refletido na limitada capacidade de suas aeronaves (e.g., com menos de 20 assentos). Além disso, tais companhias também não eram coligadas a outras companhias aéreas com atuação em outro(s) negócio(s). Assim, a população de interesse se limitava a cerca de 60 ou 65 companhias aéreas (dependendo do ano). Apesar do interesse em analisar todas essas empresas, para parte delas o DOT não possuía todas as informações. Então, a amostra foi constituída por todas as companhias aéreas com disponibilidade de informações no DOT no período analisado. Isso levou a uma amostra de 45 companhias aéreas, ou seja, cerca de 70\% da população de companhias aéreas dos Estados Unidos com estratégia de diversificação relacionada. Para validar que as informações compreendiam, de fato, negócios relacionados, utilizou-se a mesma abordagem de outras pesquisas (e.g., Rawley, 2010; Sakhartov \& Folta, 2014) que operacionalizaram este construto a partir do código de atividade econômica - mais especificamente, o Standard Industrial Classification no nível de 2 dígitos. De fato, foi possível constatar que os negócios com os quais as empresas estavam envolvidas pertenciam à mesma classificação industrial (i.e., código SIC 45 - Transportation by Air: Air cargo carrier, scheduled; Air cargo carrier, nonscheduled; Air passenger carrier, scheduled; Flying charter service).

Como as companhias aéreas da amostra podiam estar coligadas a um mesmo grupo econômico (i.e., holding/corporação), analisá-las sem levar isso em consideração não refletiria a real diversificação dos negócios. Desse modo, as 45 companhias aéreas foram agrupadas de acordo com os grupos econômicos aos quais pertenciam, resultando em 21 corporações, quais sejam: American Airlines (AMR); Delta Airlines; Southwest Airlines Co.; Airtran Airways Corporation; Alaska Airlines; 
Continental Airlines; US Airways; Frontier Airlines; Chautauqua; Northwest; Aloha Air; Hawaiian Airlines; America West Airlines; Vanguard Airlines; Spirit Airlines; Reeve Aleutian Airways; TWA Airlines; ATA Airlines; United Airlines; Midwest Airline; e Air Wisconsin Airlines Corp. Assim, os parâmetros operacionais e de lucratividade dos negócios foram agregados considerando as estruturas de capital e de propriedade de cada corporação, sem desprezar informações das 45 companhias aéreas. Portanto, o trabalho contemplou todas as companhias aéreas para as quais havia informação disponível no período estudado, gerando 204 observações firma-trimestre.

\section{Variável dependente}

Desempenho: O desempenho das corporações foi mensurado como o somatório do lucro líquido das companhias aéreas coligadas em um dado trimestre. Optou-se por uma métrica de desempenho que não fosse exclusiva do setor, como o yield (Hurdle, Johnson, Joskow, Werden, \& Williams, 1989) ou o RASM (D. Miller \& Chen, 1994), para seguir o que a literatura de estratégia empresarial costuma adotar, ou seja, métricas contábeis ou econômicas para identificar o desempenho das firmas (Barney, 2013). A indisponibilidade de informações, entretanto, inviabilizou o uso de métricas como o ROA, o ROE ou o EBITDAR. Ainda que algumas delas pudessem ser obtidas para empresas de capital aberto, isso levaria a uma redução da amostra. Por exemplo, em trabalho recente sobre o setor, Hannigan, Hamilton e Mudambi (2015) optaram por trabalhar com companhias aéreas com capital aberto nos Estados Unidos, e o número de resultante de firmas na amostra deles foi cerca de $25 \%$ do número de companhias aéreas presentes na amostra da presente pesquisa. Optou-se, portanto, por uma métrica que assegurasse uma amostragem mais abrangente e, ao mesmo tempo, alinhada ao que se usa na literatura de estratégia, ainda que tal métrica não seja livre de críticas, como a suscetibilidade às arbitrariedades da administração das firmas, aos vieses de curto prazo, à subvalorização de recursos intangíveis (Collins, Román, \& Chan, 2011) ou, ainda, à estrutura de capital das firmas (Barney, 2013).

\section{Variável independente}

Foco: Para medir o grau de diversificação das firmas da amostra, foi empregada uma das métricas mais utilizadas nos trabalhos empíricos até então realizados, qual seja: o índice de Herfindahl (Villalonga, 2004). Esse índice foi calculado a partir do percentual das receitas advindas de cada unidade de negócio reportado pelo grupo econômico; mais especificamente, o índice de Herfindahl é derivado da soma das multiplicações, por elas mesmas, da participação de cada negócio da firma na receita total, ou seja, o índice é o somatório do quadrado das participações $(P)$ da firma $i$ em cada negócio $j: \mathrm{H}_{i}=$ $\sum_{\mathrm{j}=1}^{\mathrm{k}}\left(P_{i j} * P_{i j}\right)$. Portanto, o índice de Herfindahl possui valores que vão de 0 a 1 , onde valores próximos à unidade representam menores graus de diversificação, ou seja, empresas focadas ou de único negócio. Nesse sentido, para facilitar a interpretação dos resultados da regressão, a variável foi denominada de Foco por retratar mais diretamente o efeito estimado. Assim como com a variável dependente, a base de medição foi trimestral. Tendo em vista o comportamento curvilíneo da relação entre a variável foco e a variável dependente, a variável foco também foi inserida no modelo de regressão em sua forma quadrática (Haans, Pieters, \& He, 2016).

\section{Variáveis de controle}

Para evitar que outros fatores pudessem confundir os efeitos da diversificação sobre o desempenho, foram incluídas variáveis de controle normalmente empregadas na literatura especializada (Tabela 1). 
Tabela 1

Variáveis de Controle Utilizadas na Especificação do Modelo

\begin{tabular}{|c|c|c|}
\hline Variável de Controle & Descrição & Referências \\
\hline Barreiras à Entrada & $\begin{array}{l}\text { Média de voos diários diretos oferecidos em cada mercado } \\
\text { (i.e., par de cidades origem-destino). }\end{array}$ & $\begin{array}{l}\text { Berry (1992); Huse e } \\
\text { Oliveira (2012) }\end{array}$ \\
\hline Poder de Mercado & $\begin{array}{l}\text { Market share médio dos mercados, calculado a partir da } \\
\text { consolidação de } 34.700 \text { pares de cidades origem-destino } \\
\text { (O\&D), ou seja, é a média do percentual de passageiros } \\
\text { transportados pela firma em relação ao total transportado } \\
\text { em cada mercado O\&D. Os passageiros são rastreados a } \\
\text { partir do seu aeroporto de origem até seu destino (O\&D), } \\
\text { independentemente das conexões que tenham sido feitas. }\end{array}$ & $\begin{array}{l}\text { Berry (1992); Bilotkach } \\
\text { e Lakew (2014) }\end{array}$ \\
\hline $\begin{array}{l}\text { Flexibilidade dos } \\
\text { Recursos }\end{array}$ & $\begin{array}{l}\text { Medido a partir do índice de Herfindahl calculado com base } \\
\text { no número de aeronaves pertencentes a cada categoria de } \\
\text { aeronave, em função do número de assentos (de menos de } \\
30 \text { até acima de } 400 \text { assentos) e do tipo de propulsão } \\
\text { (turboélice ou jatos). Mais especificamente, os segmentos } \\
\text { de capacidade utilizados foram: TP<30, TP31-60, TP61-90, } \\
\text { J31-60, J61-90, J91-120, J121-150, J151-180, J181-210, } \\
\text { J211-300, J301-400 e J }>401 \text {, em que "TP" corresponde a } \\
\text { aeronaves com motorização turboélice e "J" corresponde a } \\
\text { aeronaves a jato (a numeração corresponde ao número de } \\
\text { assentos da aeronave). Valores próximos a } 1 \text { correspondem } \\
\text { a firmas contendo aeronaves com números de assentos } \\
\text { muito próximos, ou seja, com recursos pouco flexíveis. } \\
\text { Ainda que esta proxy não retrate a flexibilidade do uso da } \\
\text { aeronave em outras rotas conceitualmente diferentes (i.e., } \\
\text { intercontinental vs. regional), ela captura a variabilidade da } \\
\text { frota para uso em outros fins (i.e., carga, charter) em rotas } \\
\text { conceitualmente similares. }\end{array}$ & $\begin{array}{l}\text { Chatterjee e Wernerfelt } \\
\text { (1991); Givoni e } \\
\text { Rietveld (2009); Merkert } \\
\text { e Hensher (2011) }\end{array}$ \\
\hline Custos & $\begin{array}{l}\text { O combustível tende a ser um dos principais responsáveis } \\
\text { pelos custos operacionais das companhias aéreas. Ainda que } \\
\text { os custos de coordenação sejam de particular interesse } \\
\text { quando se discute diversificação, eles não são os únicos a } \\
\text { afetarem o desempenho das firmas. Além disso, o uso de } \\
\text { despesas administrativas, como proxy para custos de } \\
\text { coordenação, demandaria a limitação da amostra para } \\
\text { empresas de capital aberto. Optou-se, portanto, por } \\
\text { controlar por um custo que não limitasse o tamanho da } \\
\text { amostra. }\end{array}$ & $\begin{array}{l}\text { Meland (2014); Zou, } \\
\text { Elke, Hansen e Kafle } \\
(2014)\end{array}$ \\
\hline $\begin{array}{l}\text { Estágios do Ciclo de } \\
\text { Negócios do Setor }\end{array}$ & $\begin{array}{l}\text { Para o controle da ciclicidade dos negócios no setor, foram } \\
\text { utilizadas variáveis do tipo dummy, sendo uma delas } \\
\text { utilizada para o ano de } 1996 \text {, período pertencente à fase de } \\
\text { expansão, e a outra utilizada para o ano de } 1999 \text {, período } \\
\text { pertencente à fase de declínio da taxa de crescimento do } \\
\text { setor. }\end{array}$ & $\begin{array}{l}\text { Holloway (2008); } \\
\text { Pierson e Sterman } \\
(2013)\end{array}$ \\
\hline $\begin{array}{l}\text { Desempenho } \\
\text { Defasado }(\mathrm{t}-1)\end{array}$ & $\begin{array}{l}\text { Foi utilizado o desempenho da firma no mesmo trimestre do } \\
\text { ano anterior. }\end{array}$ & $\begin{array}{l}\text { Collins, Román e Chan } \\
(2011) \text {; Lemmon, } \\
\text { Roberts e Zender } \\
\text { (2008); Short, Ketchen, } \\
\text { Bennett e Toit (2006) }\end{array}$ \\
\hline
\end{tabular}




\section{Abordagem estatística}

Tendo em vista a estrutura dos dados transversais em conjunto com as medidas realizadas de forma longitudinal, foi utilizado o modelo de regressão linear múltipla com dados em painel como técnica estatística para avaliação dos dados (Wooldridge, 2010). A utilização de dados em painel possibilita o estudo da mesma unidade de corte transversal (i.e., corporação) ao longo do tempo, permitindo um controle da heterogeneidade presente nas diferentes companhias aéreas, como as características internas que permitem à firma obter desempenho superior ao longo do tempo. Além disso, esta abordagem permite uma análise da defasagem de resultados de tomadas de decisão em um determinado período de tempo analisado, uma vez que o reflexo de determinada ação pode não ocorrer, necessariamente, no mesmo período de tempo desta ação.

O modelo de regressão completo com dados em painel é dado por:

$$
\text { Desempenho }_{i t}=\beta_{0}+\beta_{1} \text { Foco }_{\mathrm{it}}+\beta_{2} \text { Foco }_{\mathrm{it}}^{2}+\boldsymbol{\delta} \mathbf{Z}_{\mathrm{it}}+\pi P_{i t-1}+\alpha_{i}+\varepsilon_{i t}
$$

em que a variável dependente é o desempenho da firma $\mathrm{i}(\mathrm{i}=1,2, \ldots, \mathrm{n})$ no instante de tempo $\mathrm{t}$ (cada trimestre dos anos de 1995, 1996, 1998, 1999, 2001 e 2002). As variáveis explicativas são o foco (ou diversificação) da firma i no tempo t e seu quadrado (para representar a possível relação de Uinvertido com o desempenho); o vetor coluna $\mathbf{Z}_{\mathbf{i t}}$ contém os valores das variáveis de controle para a firma i no tempo $t ; \mathrm{P}_{\mathrm{it}-1}$ controla o desempenho passado da firma i; $\alpha$ representa o efeito não observável relacionado à firma i; e $\varepsilon$ é o erro idiossincrático.

A estimação dos parâmetros do modelo foi feita via método dos momentos generalizado - GMM (do inglês Generalized Method of Moments). Enquanto a estimação por máxima verossimilhança comumente assume uma distribuição normal multivariada, a estimação por GMM não demanda o conhecimento da distribuição dos dados (Hall, 2005). A estimação por GMM, portanto, não impõe mais restrições aos dados, conferindo maior flexibilidade na estimação dos parâmetros. Além disso, o GMM permite que seja feita a estimação sem viés dos coeficientes de um painel dinâmico, ou seja, quando a defasagem da variável resposta (neste caso, o desempenho) é utilizada como variável explicativa.

No entanto, a estimação do modelo especificado apresenta um desafio, pois tanto o foco pode impactar o desempenho da firma quanto o desempenho pode influenciar o foco, no sentido de que a firma pode fazer mudanças estratégicas em sua diversificação de acordo com o desempenho obtido. Dessa forma, existe uma relação bilateral entre o desempenho e o foco, que caracteriza a endogeneidade no modelo. Assim, se for usado um estimador de mínimos quadrados ordinários, os resultados serão viesados e inconsistentes (Wooldridge, 2010). Uma das formas de resolver este problema é fazer uso de variáveis instrumentais. Estas variáveis instrumentais devem ser correlacionadas com a variável explicativa endógena (i.e., Foco), mas não podem ser diretamente correlacionadas com a variável resposta (i.e., Desempenho). Como os dados a serem analisados são dados longitudinais, é natural que os instrumentos sejam as variáveis explicativas defasadas (Short, Ketchen, Bennett, \& Toit, 2006), pois o foco no instante de tempo anterior ( $\mathrm{t}-1$ ) influencia o foco no instante presente (t) (existe uma persistência nestas variáveis), mas este foco no instante anterior não influencia diretamente o desempenho no instante presente. Assim, o uso de variáveis instrumentais (ou instrumentos) no modelo garante que a estimação estatística dos parâmetros seja consistente.

Antes da estimação do modelo, foi levantada a estatística descritiva das variáveis especificadas (Tabela 2), de modo a se ter uma visão geral dos dados. Além disso, com vistas à identificação da aderência do modelo às premissas para aplicação da técnica estatística adotada, outras análises foram realizadas e, quando pertinente, ajustes foram implementados. Mais detalhes sobre essas análises são apresentados adiante na seção sobre a robustez dos resultados. 
Tabela 2

Estatística Descritiva - Períodos de Expansão, Declínio e Contração ${ }^{a}$

\begin{tabular}{lcccccc}
\hline Variável & Período & Média & Desvio padrão & Mínimo & Máximo & Observações \\
\hline Desempenho & Expansão & 33875 & 66995 & -165547 & 204877 & 62 \\
& Declínio & 55792 & 112297 & -215616 & 453281 & 72 \\
& Contração & -135946 & 244001 & -1132876 & 102298 & 70 \\
\cline { 2 - 7 } Foco & Total & -16661 & 183193 & -1132876 & 453281 & 204 \\
& Expansão & 0,8128 & 0,0850 & 0,5454 & 0,9684 & 62 \\
& Declínio & 0,8129 & 0,0863 & 0,6001 & 0,9599 & 72 \\
& Contração & 0,8076 & 0,0989 & 0,5556 & 0,9556 & 70 \\
\cline { 2 - 7 } Barreiras à entrada & Total & 0,8110 & 0,0900 & 0,5454 & 0,9684 & 204 \\
& Expansão & 3,8799 & 2,0555 & 0,7148 & 11,0395 & 62 \\
& Declínio & 3,7804 & 1,8041 & 1,1088 & 9,4756 & 72 \\
& Contração & 3,0923 & 0,8560 & 1,3934 & 5,1766 & 70 \\
\cline { 2 - 7 } Poder de mercado & Total & 3,5746 & 1,6676 & 0,7148 & 11,0395 & 204 \\
& Expansão & 0,4266 & 0,1829 & 0,1455 & 0,8122 & 62 \\
& Declínio & 0,3933 & 0,1836 & 0,1598 & 0,8858 & 72 \\
& Contração & 0,1373 & 0,0862 & 0,0267 & 0,3626 & 70 \\
\cline { 2 - 7 } & Total & 0,3156 & 0,2030 & 0,0267 & 0,8858 & 204 \\
\hline Flexibilidade & Expansão & 0,4646 & 0,2445 & 0,2294 & 1,000 & 62 \\
& Declínio & 0,4354 & 0,2246 & 0,1772 & 1,000 & 72 \\
& Contração & 0,4752 & 0,2484 & 0,1838 & 1,000 & 70 \\
\cline { 2 - 7 } & Total & 0,4579 & 0,2385 & 0,1772 & 1,000 & 204 \\
\cline { 2 - 7 } & Expansão & 115520 & 109536 & 45 & 358315 & 62 \\
& Declínio & 89654 & 93695 & 4027 & 306168 & 72 \\
& Total & 105911 & 110547 & 0 & 474054 & 204 \\
\hline
\end{tabular}

Nota. ${ }^{a}$ Os períodos de expansão, declínio e contração correspondem aos anos de 1996, 1999 e 2002, respectivamente.

\section{Análise dos Dados}

A partir do levantamento das estatísticas descritivas dos dados (Tabela 2), foi possível identificar que, coletivamente, houve um aumento nominal de cerca de $65 \%$ no desempenho médio das firmas do período de expansão (1996) para o período de declínio (1999). Por outro lado, no período de retração (2002), as firmas apresentaram prejuízos, com seus desempenhos sofrendo uma queda nominal de aproximadamente $345 \%$ em relação ao mesmo trimestre do ano anterior. Também foi possível observar um baixo grau médio de diversificação dos negócios (i.e., foco de cerca de 0,80 ), caracterizando um setor com firmas com negócio dominante - i.e., receita de um dos negócios maior ou igual a 70\% da receita total (Collis \& Montgomery, 2004). Esta característica se mostrou estável na amostra no período de tempo estudado. Isso reforça um padrão de posicionamento estratégico no setor que resiste a movimentos que afastem a firma de seu negócio central e esse padrão parece independer do momento em que se encontra o setor. Tal característica não difere de outros trabalhos sobre a indústria americana 
de transporte aéreo (e.g., Hannigan et al., 2015), o que, de certo modo, ratifica a representatividade da amostra e consequente validade externa da pesquisa. Foi possível constatar ainda que a amplitude da diversificação entre as firmas da amostra não varia muito ao longo do tempo, havendo sempre empresas muito focadas no transporte regular de passageiros e outras empresas com maior dispersão de suas receitas entre os negócios de transporte de carga, transporte regular e voos fretados. A análise da variável Foco também permitiu observar que ela tem assimetria negativa (i.e., concentração nos maiores valores), o que ratifica o uso do GMM como técnica de estimação dos parâmetros do modelo, pois esta técnica relaxa a suposição acerca da distribuição normal dos erros do modelo.

Em função da natureza longitudinal dos dados, o teste de Hausman (1978) foi utilizado para a escolha quanto ao uso de efeitos fixos ou aleatórios para a estimação da regressão com dados em painel. No caso deste trabalho, os estimadores obtidos por efeitos fixos ou por efeitos aleatórios mostraram-se consistentes, porém optou-se pelos resultados dos estimadores gerados a partir de efeitos aleatórios, pois estes são mais eficientes do ponto de vista econométrico (Wooldridge, 2010). Tendo em vista que a análise de resíduos revelou a existência de heterocedasticidade, os modelos foram reestimados utilizando os erros padrões robustos calculados pelo método de White (Tabela 3).

Tabela 3

Impacto da Diversificação Relacionada no Desempenho (Efeitos Aleatórios)

\begin{tabular}{|c|c|c|c|c|}
\hline Variável & Modelo 1 & Modelo 2 & Modelo 3 & Modelo 4 \\
\hline \multirow[t]{2}{*}{ Foco } & & & 159456,9 & $3768569 * *$ \\
\hline & & & $(113614,7)$ & $(1560005)$ \\
\hline \multirow[t]{2}{*}{ Foco $^{\wedge 2}$} & & & & $-2284470 * *$ \\
\hline & & & & (1002089) \\
\hline \multirow[t]{2}{*}{ Barreiras à Entrada } & 961,73 & $-2937,99$ & $-906,68$ & 4136,29 \\
\hline & $(5704,25)$ & $(3259,53)$ & $(2674,89)$ & $(6295,38)$ \\
\hline \multirow[t]{2}{*}{ Poder de Mercado } & $150501,70 * *$ & $52607,57 * *$ & $66608,79 * *$ & $80215,46^{*}$ \\
\hline & $(62256,95)$ & $(23903,77)$ & $(27149,82)$ & $(43280,50)$ \\
\hline \multirow[t]{2}{*}{ Flexibilidade } & 56399,63 & 22665,10 & $-8208,96$ & 34592,31 \\
\hline & $(50627,10)$ & $(31180,21)$ & $(22968,57)$ & $(81210,28)$ \\
\hline \multirow[t]{2}{*}{ Custos } & $-0,34$ & $-0,07$ & $-0,11$ & $-0,42$ \\
\hline & $(0,35)$ & $(0,17)$ & $(0,17)$ & $(0,42)$ \\
\hline \multirow[t]{2}{*}{ Expansão } & $131154,90 * * *$ & $44036,01 * *$ & 38205,13 & $44964,98 * *$ \\
\hline & $(25818,59)$ & $(19271,78)$ & $(17532,57) * *$ & $(19352,83)$ \\
\hline \multirow[t]{2}{*}{ Declínio } & $148324,80^{* * *}$ & $49156,76^{* * * *}$ & $42872,56^{* *}$ & $42087,82 * *$ \\
\hline & $(28527,04)$ & $(16774,48)$ & $(18120,76)$ & $(20235,37)$ \\
\hline \multirow[t]{2}{*}{ Desempenho (t-1) } & & $0,67 * * *$ & $0,66^{* * *}$ & $0,59 * * *$ \\
\hline & & $(0,11)$ & $(0,11)$ & $(0,11)$ \\
\hline \multirow[t]{2}{*}{ Constante } & $-150268,5 * * *$ & $-44481,7^{*}$ & $-163052,9^{*}$ & $-1582542,0 * *$ \\
\hline & $(29898,84)$ & $(17697,52)$ & $(94448,32)$ & $(613281,60)$ \\
\hline Número de Observações & 204 & 201 & 201 & 201 \\
\hline $\mathrm{R}^{2}$ & 0,29 & 0,60 & 0,60 & 0,59 \\
\hline $\mathrm{R}^{2}$ Ajustado & 0,27 & 0,58 & 0,59 & 0,58 \\
\hline Durbin Watson & 0,66 & 2,21 & 2,22 & 2,26 \\
\hline Estatística J & 0 & 0 & 0 & 0 \\
\hline
\end{tabular}

Nota. *significante a $10 \%,{ }^{* *}$ significante a $5 \%$ e $* * *$ significante a $1 \%$. Erros padrões robustos reportados entre parênteses. 
A Tabela 3 contém os resultados dos quatro modelos estimados para analisar a relação entre o foco e o desempenho no período avaliado. O Modelo 1 possui somente as variáveis de controle discutidas na revisão de literatura, mas sem a variável desempenho defasado em um período, ou seja, no mesmo trimestre do ano anterior; o Modelo 2 acrescenta a variável desempenho defasado como controle; o Modelo 3 contém a variável foco com relação linear com o desempenho, além de todas as variáveis de controle; o Modelo 4 é o modelo principal e apresenta a variável foco e seu quadrado para testar a associação em forma de U invertido do foco com o desempenho, além de todas as variáveis de controle.

Cabe notar que o fato de as firmas serem mais focadas (ou diversificadas) não foi estatisticamente significante para explicar o desempenho das companhias aéreas quando a relação considerada entre as variáveis em questão foi tratada como linear (Modelo 3). Entretanto, quando foi considerada a relação quadrática entre o foco e o desempenho (Modelo 4), a significância estatística apareceu. Tendo em vista o coeficiente positivo relativo ao foco e o coeficiente negativo relativo ao foco ao quadrado, os resultados ratificam a forma de U-invertido da relação entre o foco (ou a diversificação) e o desempenho das firmas. Ou seja, os resultados não permitem rejeitar a hipótese de curvilinearidade entre o grau de diversificação relacionada e o desempenho (mesmo controlando pelo desempenho passado).

Entre as variáveis de controle, nota-se, no modelo principal (Modelo 4), que todos os sinais estão de acordo com o esperado, ou seja, as barreiras à entrada, o poder de mercado, a flexibilidade dos recursos e o desempenho defasado exercem influência positiva no lucro das empresas da amostra, enquanto os custos impactam negativamente a lucratividade. No entanto, a ausência de significância estatística para a maioria delas não permite que se afirme que possuem um efeito sistemático sobre o desempenho. Por outro lado, e como esperado, as firmas apresentaram desempenho médio melhor nos períodos de expansão e de declínio do que no período de contração. Há que se notar ainda que o controle pelo desempenho passado melhora a capacidade de explicação dos modelos.

\section{Robustez dos resultados}

Tendo em vista a necessidade de não violação dos pressupostos da técnica estatística, além da correção da heterogeneidade da variância dos resíduos pelo método de White (gerando erros padrões robustos), outras características das estimações foram averiguadas. De acordo com o teste Jarque-Bera, existem indícios de que a normalidade dos erros não seja válida $(\mathrm{p}<0,01)$. Porém, o tamanho da amostra confere robustez aos resultados mesmo sem a validade da distribuição Normal para os erros (Thadewald \& Büning, 2007). A estatística de Durbin-Watson serve para verificar a existência de correlação serial nos erros dos modelos e, conforme apresentado nos resultados da regressão original (Tabela 3), esta estatística assume valores próximos de 2 , especialmente após o controle do tempo defasado, o que indica que a estrutura de correlação entre os tempos foi devidamente modelada (Wooldridge, 2010). Além disso, os resultados também revelaram que a estatística $\mathrm{J}$ possui valores próximos a zero em todos os modelos, o que indica que eles foram adequadamente ajustados em termos dos instrumentos utilizados (Hall, 2005).

Também foram verificados os graus de correlação entre as variáveis explicativas (Tabela 4). É possível observar que o modelo não apresenta forte multicolinearidade (a maior correlação é de 0,4289, entre as variáveis custo e flexibilidade). Além disso, foram calculados os fatores de inflação da variância (FIV) e o maior deles foi igual a 2,19 (relacionado à explicação do market share em relação às outras variáveis explicativas). Como os FIVs não apresentaram valores superiores a cinco, que é o limite para indicar presença de multicolinearidade (Wooldridge, 2010), o modelo está isento desse problema. 
Tabela 4

Matriz de Correlação das Variáveis do Modelo

\begin{tabular}{lcccccc}
\hline Variável & $(1)$ & $(2)$ & $(3)$ & $(4)$ & $(5)$ & $(6)$ \\
\hline (1) Foco & 1 & & & & & \\
(2) Barreiras à entrada & $-0,1540^{* *}$ & 1 & & & & \\
(3) Poder de mercado & $-0,1281^{*}$ & $0,3208^{* *}$ & 1 & & & \\
(4) Flexibilidade & $0,3568^{* *}$ & $-0,0168$ & $-0,0591$ & 1 & & \\
(5) Custo & 0,0121 & $0,2843^{* *}$ & 0,0025 & $-0,4289^{* *}$ & 1 & \\
(6) Desempenho anterior & 0,1177 & 0,0602 & $0,3608^{* *}$ & $0,1342^{*}$ & $-0,2138^{* *}$ & 1 \\
\hline
\end{tabular}

Nota. * significante a $10 \%, * *$ significante a $5 \%$ e $* * *$ significante a $1 \%$.

Para analisar a presença e o possível efeito dos valores aberrantes, foram utilizados os resíduos studentizados, já que Riazoshams, Habshah e Adam (2009) mostram que o resíduo studentizado e a distância de Cook são capazes de identificar de forma consistente os valores aberrantes em modelos de regressão não linear. Foram identificados oito valores aberrantes utilizando o valor 2,5, em módulo, como ponto de corte (Riazoshams, Habshah, \& Adam, 2009). A partir dessa análise, gráficos de dispersão (não apresentados aqui por restrição de espaço) foram construídos e foram estimadas as curvas da correlação (entre as variáveis desempenho e foco) com e sem valores aberrantes. O que se observou foi que, mesmo após desconsiderar os valores aberrantes, o padrão de correlação (i.e., formato da curva) entre desempenho e foco não sofreu alteração, ratificando os achados da análise de regressão.

Tendo em vista que é comum, nos trabalhos empíricos sobre o setor de transporte aéreo, a análise de regressões controlando por efeitos fixos (e.g., Meland, 2014), os modelos foram reestimados (Tabela 5). É possível constatar, nesta análise suplementar, que independentemente dos efeitos (fixos ou aleatórios), o padrão dos resultados se mantém, ou seja, a relação entre o foco (ou diversificação) e o desempenho segue um padrão de U-invertido.

Procurou-se, ainda, identificar se especificações alternativas do modelo poderiam afetar a análise original (não apresentadas aqui por restrições de espaço). Tendo em vista que, no momento de construção da variável poder de mercado, foi necessário delimitar as rotas (origem e destino) atendidas pelas companhias aéreas, optou-se por empregar esta métrica (i.e., número total de pares de cidades servidos pela empresa) como uma proxy para o tamanho da firma. Ainda que não fosse uma métrica tão precisa quanto o assento.kilômetro (ASK) para caracterizar o tamanho das companhias aéreas, ela já havia sido utilizada na literatura de estratégia para tal propósito (Reeven \& Pennings, 2016), podendo ser obtida com relativa facilidade (em função da construção da variável poder de mercado) e retratando, em boa medida, o fenômeno de interesse. Assim, o número total de pares de cidades servidos pela empresa foi empregado tanto como uma variável de controle quanto como um elemento para padronizar as variáveis desempenho e custo. A atenção específica que essa abordagem demandou foi que a nova variável apresentou correlação elevada com a variável custo (i.e., 0,7966**). Estimou-se, então, dois modelos (com ou sem a variável custo). Independentemente da especificação adotada, o padrão de relacionamento entre o foco (ou a diversificação) e o desempenho se manteve o mesmo e isso se aplicou também aos modelos em que as variáveis desempenho e custo foram padronizadas. 
Tabela 5

Impacto da Diversificação Relacionada no Desempenho (Efeitos Fixos)

\begin{tabular}{|c|c|c|c|c|}
\hline Variável & Modelo 5 & Modelo 6 & Modelo 7 & Modelo 8 \\
\hline \multirow[t]{2}{*}{ Foco } & & & 243856,1 & $4469116,4^{* *}$ \\
\hline & & & $(157986,9)$ & $(1839825,3)$ \\
\hline \multirow[t]{2}{*}{ Foco $^{\wedge 2}$} & & & & $-2707167,2^{* *}$ \\
\hline & & & & $(1229698,0)$ \\
\hline \multirow[t]{2}{*}{ Barreiras à Entrada } & 11996,2 & 1542,0 & 4021,4 & 1596,9 \\
\hline & $(11057,8)$ & $(6757,9)$ & $(5934,5)$ & $(7516,4)$ \\
\hline \multirow[t]{2}{*}{ Poder de Mercado } & $339219,5^{* * *}$ & $107877,2 * *$ & $126745,3^{* *}$ & 65737,75 \\
\hline & $(96388,9)$ & $(46313,4)$ & $(50393,7)$ & $(75569,5)$ \\
\hline \multirow[t]{2}{*}{ Flexibilidade } & 10965,9 & 2592,8 & $-28276,9$ & 151553,6 \\
\hline & $(97230,4)$ & $(62742,1)$ & $(58433,6)$ & $(109495,2)$ \\
\hline \multirow[t]{2}{*}{ Custos } & $-0,89$ & $-0,32$ & $-0,39$ & $-1,02 *$ \\
\hline & $(0,55)$ & $(0,39)$ & $(0,41)$ & $(0,52)$ \\
\hline \multirow[t]{2}{*}{ Expansão } & $74277,3^{* *}$ & $36946,6^{* *}$ & $29191,3^{*}$ & $52714,6^{*}$ \\
\hline & $(29576,5)$ & $(18416,2)$ & $(17353,5)$ & $(33185,15)$ \\
\hline \multirow[t]{2}{*}{ Declínio } & $79435,0^{* *}$ & $36451,1 * *$ & $28413,1 *$ & 41888,1 \\
\hline & $(33330,8)$ & $(16532,3)$ & $(18062,1)$ & $(28161,9)$ \\
\hline \multirow[t]{2}{*}{ Desempenho (t-1) } & & $0,63^{* * *}$ & $0,61 * * *$ & $0,56^{* * *}$ \\
\hline & & $(0,11)$ & $(0,11)$ & $(0,10)$ \\
\hline \multirow[t]{2}{*}{ Constante } & $-130670,0^{* *}$ & $-38565,8$ & $-226217,7^{*}$ & $-1845896,0 * *$ \\
\hline & $(52823,7)$ & $(33240,3)$ & $(140809,8)$ & $(720590,3)$ \\
\hline Número de Observações & 204 & 201 & 201 & 201 \\
\hline $\mathrm{R}^{2}$ & 0,33 & 0,59 & 0,59 & 0,65 \\
\hline $\mathrm{R}^{2}$ Ajustado & 0,31 & 0,57 & 0,57 & 0,61 \\
\hline Durbin Watson & 0,79 & 1,94 & 2,02 & 2,03 \\
\hline Estatística J & 0 & 0 & 0 & 0 \\
\hline
\end{tabular}

Nota. *significante a $10 \%$, **significante a $5 \%$ e $* * *$ significante a $1 \%$. Erros padrões robustos reportados entre parênteses.

Além de padronizar as variáveis desempenho e custos pelo número de mercados atendidos pela firma, aquelas variáveis também foram padronizadas pela receita líquida de cada corporação. Tal abordagem reflete a análise vertical de indicadores de desempenho das firmas comumente empregada nas literaturas de finanças e contabilidade (e.g., Gitman, 2008). Os resultados, entretanto, não sofreram alterações; a relação curvilínea também foi observada nesta abordagem. Portanto, os resultados se mostraram consistentes mesmo diante de abordagem econométrica ou de especificação de modelo alternativas. 


\section{Discussão dos Resultados}

Os achados desta pesquisa revelaram que tanto o coeficiente da variável foco quanto o coeficiente de seu quadrado são estatisticamente significantes em diferentes especificações do modelo. Assim, não é possível rejeitar a hipótese de que a relação entre o foco e o desempenho das empresas se dá na forma quadrática. Isso é relevante, pois, embora a literatura popular de negócios já tenha pontuado os vários desafios que as organizações possuem para expandir suas fronteiras organizacionais, a literatura científica de estratégia tem dado mais ênfase para as dificuldades que podem ser trazidas por movimentos distantes do negócio original, isto é, as dificuldades impostas pela diversificação nãorelacionada (Helfat \& Eisenhardt, 2004). Com isso, o entendimento das corporações com negócios relacionados acaba sendo restrito. A presente pesquisa, entretanto, sugere que é, no mínimo, limitada a discussão sobre a estratégia de diversificação se dar apenas em torno da dicotomia não-relacionada $v s$. relacionada.

Hannigan et al. (2015) observaram, recentemente, que níveis crescentes de receita de outros negócios (que não o transporte regular de passageiros) impactam negativamente o desempenho global das companhias aéreas. A presente pesquisa está alinhada com tal evidência, mas vai além ao identificar que existe um nível de variação nas receitas que maximiza o desempenho das firmas. Por um lado, as firmas que buscam aproveitar alguma folga em seus recursos são capazes de alcançar desempenhos superiores mesmo diante de variações nas condições do mercado. Por outro lado, a transição da firma para crescentes níveis de diversificação compromete o seu desempenho. Ou seja, os resultados mostram que, em ambientes nos quais os fatores de mercado estão disponíveis, mesmo a estratégia de diversificação relacionada pode impactar negativamente o desempenho. Na medida em que o negócio principal do grupo econômico passa a ter menor participação relativa na receita total, os maiores esforços de coordenação e de processamento de informação geram custos que não parecem ser desprezíveis; no caso da amostra estudada, o desconto da diversificação já ocorre em níveis relativamente baixos de diversificação (Rawley, 2010; Teece, 1982).

Boa parte da literatura especializada atribui aos conflitos de agência o motivo para a não criação de valor na diversificação (Rawley, 2010). A literatura, apesar de reconhecer, não dá tanta atenção ao impacto negativo que o desempenho das firmas pode ter quando elas expandem suas fronteiras horizontais de forma relacionada. Se, por um lado, Zhou (2011) já tinha reforçado tal argumento, as evidências para sustentar essa afirmação ainda eram escassas. A autora havia identificado a probabilidade de uma firma entrar ou não em um dado negócio relacionado em função do grau de complexidade de compartilhamento de insumos entre o negócio alvo e o negócio de origem. Esta pesquisa suplementa os achados reportados na literatura ao atestar que a crescente complexidade decorrente da maior representatividade dos negócios adjacentes pode, em algum momento, sobrepor os benefícios proporcionados pela diversificação relacionada.

A Figura 1 mostra que, em diferentes momentos do ciclo de negócios do setor (i.e., diferentes curvas), o melhor desempenho ocorre quando o grau de concentração de negócios é cerca de 0,83 . Esse valor é ligeiramente superior à média do setor $(0,81)$, conforme apresentado na estatística descritiva (Tabela 2), sugerindo que as corporações neste setor são muito sensíveis aos efeitos do uso de seus recursos (i.e., aeronaves) nos negócios em que atuam. De certo modo, isso reforça a noção prevalente na literatura de que a estratégia de diversificação relacionada, por manter alguma flexibilidade dos recursos (Chatterjee \& Wernerfelt, 1991), permite a realocação dos mesmos em melhores oportunidades de investimento. De certo modo, isso sugere que a operacionalização das interdependências entre os negócios é crítica para o desempenho, especialmente no momento de declínio do mercado. Em alguma medida, os achados desta pesquisa também corroboram as evidências de Markides e Williamson (1994), que chamam a atenção para o fato de a heterogeneidade no desempenho das firmas com estratégia de diversificação relacionada ser decorrente de sua capacidade de utilizarem seus ativos estratégicos. 


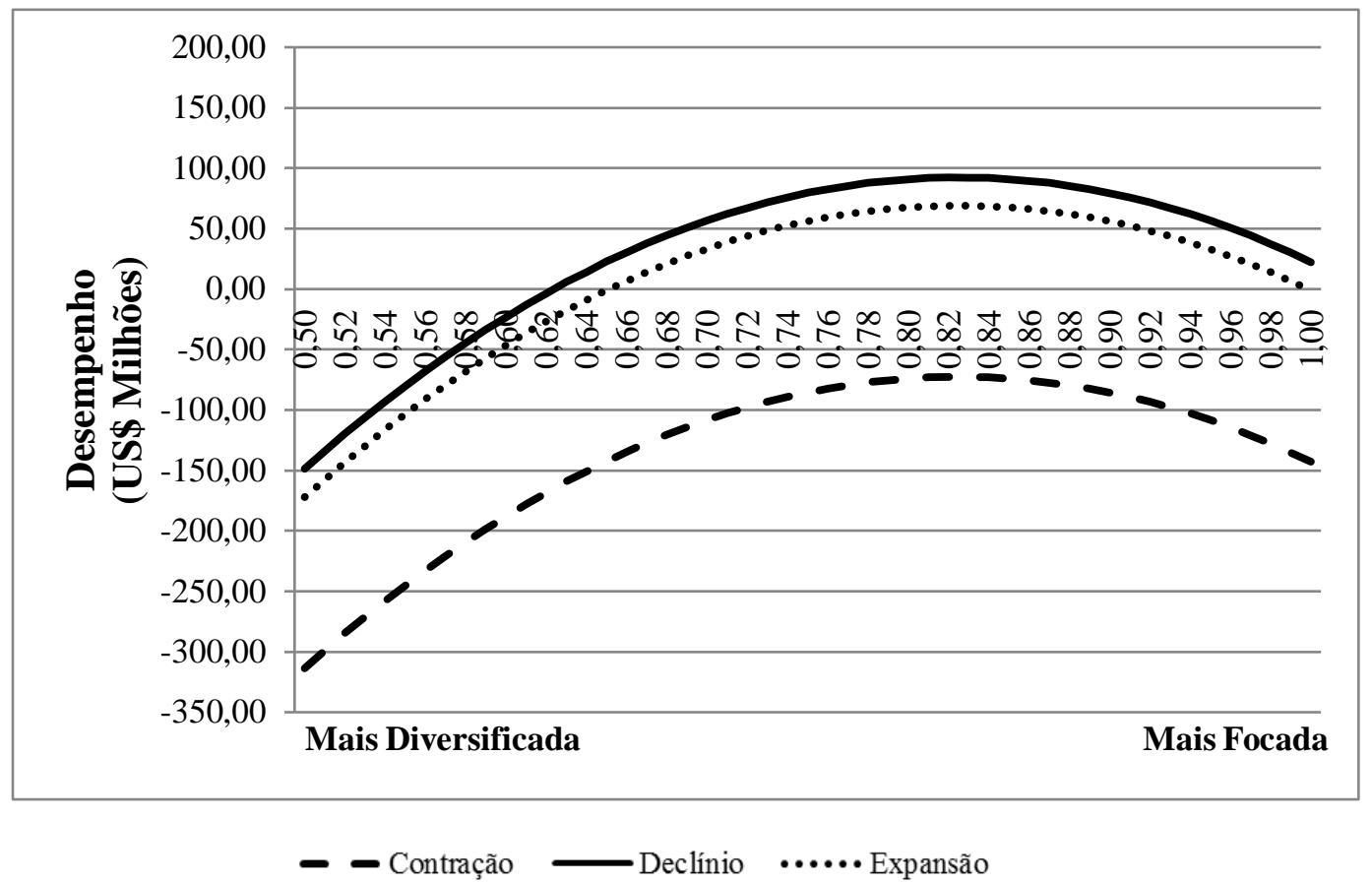

Figura 1. Efeitos do Afastamento do Negócio Principal no Desempenho Fonte: Modelo 4 (Tabela 3).

Em particular, os recursos analisados nesta pesquisa são tipicamente tangíveis e, portanto, não são recursos livres de escala (i.e., non-scale free resources) para uso na corporação, de tal modo que seu valor varia em função da melhor alternativa renunciada e na qual eles poderiam ser empregados (Levinthal \& Wu, 2010), ou seja, as decisões de diversificação notadamente envolvem custos de oportunidade (Mackey \& Barney, 2013). A estratégia empírica deste trabalho, porém, não permite avaliar a realocação dos recursos, ou seja, avaliar se as firmas apresentaram economias de escopo intertemporais (Helfat \& Eisenhardt, 2004). A realocação dos recursos está sujeita a determinados incentivos (inducements) que podem impactar positivamente o desempenho se a interação entre eles superar os custos de realocação dos recursos não livres de escala (Sakhartov \& Folta, 2015). Não surpreende, portanto, que o nível ótimo de desempenho seja alcançado em um mesmo nível de diversificação, independentemente da situação do ciclo de negócios, mas que os desempenhos positivos sejam alcançados em variadas magnitudes de diversificação, dependendo das condições de mercado.

No geral, as evidências aqui encontradas alertam para uma possível armadilha (i.e., armadilha da diversificação relacionada) nas proposições normativas da literatura de estratégia corporativa que tendem a ignorar as condições de fronteira da estratégia de diversificação relacionada. Este trabalho, portanto, se junta a esforços mais recentes (e.g., Kumar, 2013; Levinthal \& Wu, 2010; Rawley, 2010; Sakhartov \& Folta, 2014, 2015; Zhou, 2011) para oferecer melhor compreensão sobre a variabilidade do desempenho, mesmo quando as firmas optam pela estratégia de diversificação relacionada.

\section{Conclusões}

Esta pesquisa chama a atenção para um fenômeno pouco explorado na literatura de estratégia, mas que tem começado a despertar maior interesse da comunidade acadêmica (e.g., Kumar, 2013; Levinthal \& Wu, 2010; Rawley, 2010; Sakhartov \& Folta, 2014, 2015; Zhou, 2011): o entendimento dos fatores que explicam a heterogeneidade de desempenho das firmas com estratégia de diversificação relacionada. Para tanto, a pesquisa avaliou se o aumento no escopo dos negócios, de firmas diversificadas relacionadamente, impacta o desempenho. A análise foi baseada em uma amostra que 
compreende cerca de 70\% das companhias aéreas dos Estados Unidos, durante um período de seis anos, com o tipo de estratégia de interesse desta pesquisa.

Do ponto de vista teórico, as evidências aqui encontradas reforçam que o afastamento do negócio central gera custos de coordenação que podem ser significativos. Este trabalho, portanto, suplementa a literatura existente, apresentando evidências de que os benefícios proporcionados pela diversificação relacionada podem ser comprometidos pelo maior grau de diversificação, que, supostamente, deve gerar maiores custos de coordenação dos negócios. O desenvolvimento teórico recente tem chamado a atenção para os desafios de se alcançar economias de escopo intertemporais (e.g., Sakhartov \& Folta, 2014, 2015). Os achados deste trabalho parecem reforçar essa proposição na medida em que o desempenho ótimo é alcançado por empresas com baixo nível de diversificação. Ainda que de forma indireta, o trabalho sinaliza que os recursos que não são livres de escala limitam sua realocação, de forma a alcançar o melhor desempenho. Em particular, a proximidade entre os negócios de atuação das firmas pode limitar os incentivos (inducements) da diversificação, de tal modo que seja difícil alcançar bom desempenho com o uso dos recursos em outras oportunidades de negócios relacionados que não o negócio principal.

Para os gestores, os resultados deste trabalho ressaltam que o discurso popular que enfatiza a criação de sinergias para justificar a estratégia de diversificação relacionada pode esconder o que aqui foi denominado de armadilha da diversificação relacionada. Ou seja, a expansão das fronteiras organizacionais gera custos que podem ser maiores do que os benefícios desse movimento estratégico, e isso pode ser tanto mais verdade quanto mais interdependentes forem os negócios. Em suma, enquanto sinergias podem emergir das interdependências entre os negócios, tais situações demandam crescentes esforços de coordenação, o que pode conferir à diversificação relacionada retornos decrescentes.

Uma boa dose de cautela deve ser adotada na interpretação dos resultados desta pesquisa. Os resultados foram gerados a partir da análise de uma indústria focal caracterizada por um nível de competição bastante elevado. Da mesma forma, as empresas do setor apresentam níveis médios de diversificação muito baixos. Ainda, a estratégia de diversificação das empresas estudadas depende muito da folga nos recursos do negócio principal. Mesmo que os custos de se afastar do negócio principal existam, a presente pesquisa não considera que ele possa ser mitigado pelas competências da corporação. Por último, a abordagem aqui adotada não leva em conta o valor de outras alternativas de investimentos, de tal forma que o efeito no desempenho aqui identificado possa estar subestimado (Mackey \& Barney, 2013). Além disso, como o trabalho não usou amplamente métricas comuns ao setor ou mesmo métricas financeiras alternativas, as inferências apresentadas são limitadas.

Portanto, mais pesquisa é necessária não somente para avaliar se os resultados são consistentes em outros contextos, mas também para empregar métricas mais comumente utilizadas no setor e para explorar aspectos que podem condicionar a relação entre a estratégia de diversificação relacionada e o desempenho.

\section{Referências}

Amihud, Y., \& Lev, B. (1981). Risk reduction as a managerial motive for conglomerate mergers. The Bell Journal of Economics, 12(2), 605-617. http://dx.doi.org/10.2307/3003575

Ansoff, H. I. (1958). A model for diversification. Management Science, 4(4), 392-414. http://dx.doi.org/10.1287/mnsc.4.4.392

Ashford, N. J., Mumayiz, S., \& Wright, P. H. (2011). Airport engineering: Planning, design, and development of 21 st century airports (4th ed.). Hoboken, NJ: John Wiley \& Sons, Inc.

Barney, J. B. (2013). Gaining and sustaining competitive advantage (4th). Harlow, Essex: Pearson. 
Barros, C. P., Liang, Q. B., \& Peypoch, N. (2013). The technical efficiency of US Airlines. Transportation Research Part A: Policy and Practice, 50, 139-148. http://dx.doi.org/10.1016/j.tra.2013.01.019

Berry, S. T. (1992). Estimation of a model of entry in the airline industry. Econometrica, 60(4), 889917. http://dx.doi.org/10.2307/2951571

Bhargava, A., \& Sargan, J. D. (1983). Estimating dynamic random effects models from panel data covering short time periods. Econometrica, 51(6), 1635-1659. http://dx.doi.org/10.2307/1912110

Bilotkach, V., \& Lakew, P. A. (2014). On sources of market power in the airline industry: Panel data evidence from the US airports. Transportation Research Part A: Policy and Practice, 59, 288305. http://dx.doi.org/10.1016/j.tra.2013.11.011

Bond, S. R. (2002). Dynamic panel data models: A guide to micro data methods and practice. Portuguese Economic Journal, 1(2), 141. http://dx.doi.org/10.1007/s10258-002-0009-9

Borenstein, S. (2011). Why can't US airlines make money? American Economic Review, 101(3), 233237. http://dx.doi.org/10.1257/aer.101.3.233

Chang, Y.-H., \& Chang, Y.-W. (2009). Air cargo expansion and economic growth: Finding the empirical link. Journal of Air Transport Management, 15(5), 264-265. http://dx.doi.org/10.1016/j.jairtraman.2008.09.016

Chatterjee, S., \& Wernerfelt, B. (1991). The link between resources and type of diversification: Theory and evidence. Strategic Management Journal, 12(1), 33-48. http://dx.doi.org/10.1002/smj.4250120104

Chiu, M. C., Wong, H. Y., \& Li, D. (2012). Roy's safety-first portfolio principle in financial risk management of disastrous events. Risk Analysis, 32(11), 597-609. http://dx.doi.org/10.1111/risa.12154

Collis, D. J., \& Montgomery, C. A. (2004). Corporate strategy: A resource-based approach (2nd ed.). Boston: McGraw-Hill/Irwin.

Collins, D. L., Román, F. J., \& Chan, H. C. (2011). An empirical investigation of the relationship between profitability persistence and firms' choice of business model: Evidence from the U.S. airline industry. Journal of Management Accounting Research, 23, 37-70. http://dx.doi.org/10.2308/jmar-10124

Eisenhardt, K. (1989). Agency theory: An assessment and review. Academy of Management Review, 14(1), 57-74. http://dx.doi.org/10.5465/AMR.1989.4279003

Furrer, O. (2015). Corporate level strategy: Theory and applications (2nd ed.). Abingdon, OXF: Routledge.

Gitman, L. J. (2008). Princípios de administração financeira (10a ed.). São Paulo: Pearson.

Givoni, M., \& Rietveld, P. (2009). Airline's choice of aircraft size - Explanations and implications. Transportation Research Part A: Policy and Practice, 43(5), 500-510. http://dx.doi.org/10.1016/j.tra.2009.01.001

Haans, R. F. J., Pieters, C., \& He, Z.-L. (2016). Thinking about U: Theorizing and testing U- and inverted U-shaped relationships in strategy research. Strategic Management Journal, 17(7), 1177-1195. http://dx.doi.org/10.1002/smj.2399

Hall, A. R. (2005). Generalized method of moments. Advanced texts in econometrics. Oxford: Oxford University Press. 
Hannigan, T. J., Hamilton, R. D., III, \& Mudambi, R. (2015). Competition and competitiveness in the US airline industry. Competitiveness Review, 25(2), 134-155. http://dx.doi.org/10.1108/CR-112014-0036

Hashai, N. (2015). Within-industry diversification and firm performance-an S-shaped hypothesis. Strategic Management Journal, 36(9), 1378-1400. http://dx.doi.org/10.1002/smj.2290

Hausman, J. A. (1978). Specification tests in econometrics. Econometrica, 46(6), 1251-1271. http://dx.doi.org/10.2307/1913827

Helfat, C. E., \& Eisenhardt, K. M. (2004). Inter-temporal economies of scope, organizational modularity, and the dynamics of diversification. Strategic Management Journal, 25(13), 12171232. http://dx.doi.org/10.1002/smj.427

Holloway, S. (2008). Straight and level: Practical airline economics (3rd ed.). Abingdon, Oxon: Ashgate Publishing.

Hurdle, G. J., Johnson, R. L., Joskow, A. S., Werden, G. J., \& Williams, M. A. (1989). Concentration, potential entry, and performance in the airline industry. The Journal of Industrial Economics, 38(2), 119-139. http://dx.doi.org/10.2307/2098526

Huse, C., \& Oliveira, A. V. M. (2012). Does product differentiation soften price reactions to entry? Journal of Transport Economics \& Policy, 46(2), 189-204. http://dx.doi.org/10.2139/ssrn.1709070

International Air Transport Association. (2013). Profitability and the air transport value chain (IATA Economics Briefing $\mathrm{n}^{\mathrm{o}}$ 10). Recuperado em 14 de dezembro, 2015, de https://www.iata.org/whatwedo/Documents/economics/profitability-and-the-air-transportvalue\%20chain.pdf

Jensen, M. C., \& Meckling, W. H. (1976). Theory of the firm: Managerial behavior, agency costs and ownership structure. Journal of Financial Economics, 3(4), 305-360. http://dx.doi.org/10.1016/0304-405x(76)90026-x

Kumar, M. V. S. (2013). The costs of related diversification: The impact of the core business on the productivity of related segments. Organization Science, 24(6), 1827-1846. http://dx.doi.org/10.1287/orsc.1120.0812

Kupfer, F., Meersman, H., Onghena, E., \& Van de Voorde, E. (2017). The underlying drivers and future development of air cargo. Journal of Air Transport Management, 61, 6-14. http://dx.doi.org/10.1016/j.jairtraman.2016.07.002

Laeven, L., \& Levine, R. (2007). Is there a diversification discount in financial conglomerates? Journal of Financial Economics, 85(2), 331-367. http://dx.doi.org/10.1016/j.jfineco.2005.06.001

Latham, S. F., \& Braun, M. (2008). Managerial risk, innovation, and organizational decline. Journal of Management, 35(2), 258-281. http://dx.doi.org/10.1177/0149206308321549

Lemmon, M. L., Roberts, M. R., \& Zender, J. F. (2008). Back to the beginning: Persistence and the cross-section of corporate capital structure. Journal of Finance, 63(4), 1575-1608. http://dx.doi.org/10.1111/j.1540-6261.2008.01369.x

Levinthal, D. A., \& Wu, B. (2010). Opportunity costs and non-scale free capabilities: Profit maximization, corporate scope, and profit margins. Strategic Management Journal, 31(7), 780801. http://dx.doi.org/10.1002/smj.845 
Liehr, M., Größler, A., Klein, M., \& Milling, P. M. (2001). Cycles in the sky: Understanding and managing business cycles in the airline market. System Dynamics Review, 17(4), 311-332. http://dx.doi.org/10.1002/sdr.226

Lintner, J. (1965). The valuation of risk assets and selection of risky investments in stock portfolios and capital budgets. Review of Economics and Statistics, 47(1), 13-37. http://dx.doi.org/10.2307/1924119

Mackey, T. B., \& Barney, J. B. (2013). Incorporating opportunity costs in strategic management research: The value of diversification and payout as opportunities forgone when reinvesting in the firm. Strategic Organization, 11(4), 347-363. http://dx.doi.org/10.1177/1476127013481447

Mackey, T. B., Barney, J. B., \& Dotson, J. P. (2017). Corporate diversification and the value of individual firms: A Bayesian approach. Strategic Management Journal, 38(2), 322-341. http://dx.doi.org/10.1002/smj.2480

Markides, C. C., \& Williamson, P. J. (1994). Related diversification, core competences and corporate performance. Strategic Management Journal, 15(Suppl. S2), 149-165. http://dx.doi.org/10.1002/smj.4250151010

Markowitz, H. (1952). Portfolio selection. Journal of Finance, 7(1), 77-91. http://dx.doi.org/10.2307/2975974

Meland, W. J. (2014). Measurement of a cost function for US airlines: Restricted and unrestricted translog models. Journal of Transport Literature, 8(2), 38-72. http://dx.doi.org/10.1590/S223810312014000200003

Merkert, R., \& Hensher, D. A. (2011). The impact of strategic management and fleet planning on airline efficiency - A random effects Tobit model based on DEA efficiency scores. Transportation Research Part A: Policy and Practice, 45(7), 686-695. http://dx.doi.org/10.1016/j.tra.2011.04.015

Merkert, R., Van de Voorde, E., \& de Wit, J. (2017). Making or breaking - Key success factors in the air cargo market. Journal of Air Transport Management, 61, 1-5. http://dx.doi.org/10.1016/j.jairtraman.2017.02.001

Miller, D., \& Chen, M.-J. (1994). Sources and consequences of competitive inertia: A study of the U.S. airline industry. Administrative Science Quarterly, 39(1), 1-23. http://dx.doi.org/10.2307/2393492

Miller, D. J. (2006). Technological diversity, related diversification, and firm performance. Strategic Management Journal, 27(7), 601-619. http://dx.doi.org/10.1002/smj.533

Palich, L., Cardinal, L. B., \& Miller, C. (2000). Curvilinearity in the diversification-performance linkage: an examination of over three decades of research. Strategic Management Journal, 21(2), 155-174. http://dx.doi.org/10.2307/3094038

Pierson, K., \& Sterman, J. D. (2013). Cyclical dynamics of airline industry earnings. System Dynamics Review, 29(3), 129-156. http://dx.doi.org/10.1002/sdr.1501

Popescu, A., Keskinocak, P., \& Mutawaly, I. (2010). The air cargo industry. In L. A. Hoel, G. Giuliano, \& M. D. Meyer (Eds.), Intermodal transportation: Moving freight in a global economy (pp. 209237). Easton, MD: Harrington-Hughes \& Associates, Inc.

Rawley, E. (2010). Diversification, coordination costs, and organizational rigidity: Evidence from microdata. Strategic Management Journal, 31(8), 873-891. http://dx.doi.org/10.1002/smj.838 
Reeven, P. van, \& Pennings, E. (2016). On the relation between multimarket contact and service quality: Mutual forbearance or network coordination? Strategic Management Journal, 37(10), 2121-2134 http://dx.doi.org/10.1002/smj.2435

Riazoshams, A. H., Habshah, B. M., Jr., \& Adam, A. M. B. (2009). On the outlier detection in nonlinear regression. International Journal of Mathematical, Computational, Physical, Electrical and Computer Engineering, 3(12), 1105-1111.

Sakhartov, A. V., \& Folta, T. B. (2014). Resource relatedness, redeployability, and firm value. Strategic Management Journal, 35(12), 1781-1797. http://dx.doi.org/10.1002/smj.2182

Sakhartov, A. V., \& Folta, T. B. (2015). Getting beyond relatedness as a driver of corporate value. Strategic Management Journal, 36(13), 1939-1959. http://dx.doi.org/10.1002/smj.2327

Scandinavian Airlines. (2013). SAS Annual Report 2013. Retrieved 19 January, 2016, from https://www.sasgroup.net/en/wp-content/uploads/sites/2/2014/09/SAS-Annual-Report-2013English.pdf

Schulmerich, M., Leporcher, Y.-M., \& Eu, C.-H. (2015). Applied asset and risk management: A guide to modern portfolio management and behavior-driven markets. Berlin: Springer. http://dx.doi.org/10.1007/978-3-642-55444-5

Sharpe, W. F. (1964). Capital asset prices: A theory of market equilibrium under conditions of risk. Journal of Finance, 19(3), 425-442. http://dx.doi.org/10.2307/2977928

Shawky, H. A., Dai, N., \& Cumming, D. (2012). Diversification in the hedge fund industry. Journal of Corporate Finance, 18(1), 166-178. http://dx.doi.org/10.1016/j.jcorpfin.2011.11.006

Short, J. C., Ketchen, D. J., Bennett, N., \& Toit, M. du (2006). An examination of firm, industry, and time effects on performance using random coefficients modeling. Organizational Research Methods, 9(3), 259-284. http://dx.doi.org/10.1177/1094428106287572

Teece, D. J. (1982). Towards an economic theory of the multiproduct firm. Journal of Economic Behavior and Organization, 3(1), 39-63. https://doi.org/10.1016/0167-2681(82)90003-8

Thadewald, T., \& Büning, H. (2007). Jarque-bera test and its competitors for testing normality - A power comparison. Journal of Applied Statistics, 34(1), 87-105. http://dx.doi.org/10.1080/02664760600994539

Villalonga, B. (2004). Diversification discount or premium? New evidence from the business information tracking series. Journal of Finance, 59(2), 475-502. http://dx.doi.org/10.1111/j.15406261.2004.00640.x

Wooldridge, J. (2010). Econometric analysis of cross section and panel data (2nd ed.). Cambridge, MA: MIT Press.

Wu, C., Hayashi, Y., \& Funck, C. (2012). The role of charter flights in Sino-Japanese tourism. Journal of Air Transport Management, 22, 21-27. http://dx.doi.org/10.1016/j.jairtraman.2012.01.005

Yang, Y., Narayanan, V. K., \& De Carolis, D. M. (2014). The relationship between portfolio diversification and firm value: The evidence from corporate venture capital activity. Strategic Management Journal, 35(13), 1993-2011. http://dx.doi.org/10.1002/smj.2190

Zhou, Y. M. (2011). Synergy, coordination costs, and diversification choices. Strategic Management Journal, 32(6), 624-639. http://dx.doi.org/10.1002/smj.889 
Zou, B., Elke, M., Hansen, M., \& Kafle, N. (2014). Evaluating air carrier fuel efficiency in the US airline industry. Transportation Research Part A: Policy and Practice, 59, 306-330. http://dx.doi.org/10.1016/j.tra.2013.12.003

\section{Dados dos Autores}

Henrique Machado Barros

Rua Tamandaré 688, 01525-000, São Paulo, SP, Brasil. E-mail: hbarros@ fei.edu.br

Adriana Bruscato Bortoluzzo

Rua Quatá 300, 04546-042, São Paulo, SP, Brasil. E-mail: adrianab@insper.edu.br

Lucas Mello de Campos Arruda

Rua Quatá 300, 04546-042, São Paulo, SP, Brasil. E-mail: 1mc_arruda@yahoo.com 